\author{
Cadernos de \\ ESTUDOS LINGUUISTICOS - (59.2), Campinas, pp. 461-480 - mai./ago. 2017
}

\title{
PROCESSOS FONOLÓGICOS NA FALA DE SUJEITOS COM SÍNDROME DE DOWN: UMA INTERPRETAÇÃO VIA GEOMETRIA DE TRAÇOS E TEORIA MÉTRICA DA SÍLABA
}

\author{
MARIAN OLIVEIRA \\ (UESB) \\ VERA PACHECO \\ (UESB) \\ LUANA PORTO PEREIRA-SOUZA \\ (UESB)
}

\begin{abstract}
RESUMO: Entre as várias descrições que a literatura especializada registra sobre as características da pessoa com síndrome de Down (SD), destacam-se o déficit cognitivo, o atraso no desenvolvimento linguístico e a fala um tanto peculiar com omissões e trocas de segmentos. $\mathrm{Na}$ produção oral, essas modificações comprometem o desempenho fonético e podem, em certa medida, comprometer a inteligibilidade da fala dessas pessoas. Considerando a importância desse aspecto para a comunicação, foi realizado o presente estudo sobre os processos fonológicos (PFs) na fala de pessoas com SD, à luz da Teoria da Geometria de Traços, delineada por Clements e Hume (1995), e da Teoria Métrica da Sílaba, proposta em Selkirk (1982), estabelecendo-se as seguintes hipóteses: a) que as trocas e as omissões encontradas na fala configuram processos fonológicos tanto de substituição quanto de estrutura silábica, e; b) que os modelos teóricos citados podem auxiliar na compreensão do PFs que eventualmente ocorrem na fala de sujeitos com SD. A pesquisa se desenvolveu a partir da análise de oitiva e transcrição fonética da produção oral de 12 sujeitos com SD, que já passaram do período de aquisição do sistema fonológico, na faixa etária entre 10 e 30 anos, posterior identificação, catalogação e análise dos processos fonológicos detectados em tais produções. Por meio do estudo feito, foi constatado que: i) com exceção de dois sujeitos que apresentaram apenas PFs de estrutura silábica, todos apresentam PFs, tanto de substituição quanto de estrutura silábica, ii) na produção oral dos sujeitos participantes, há uma tendência à simplificação de segmentos e de estruturas mais complexas, à semelhança do que ocorre durante a aquisição oral mesmo entre indivíduos adultos pesquisados; iii) há indícios de não especificação fonológica do valor de traços na fala de alguns sujeitos.
\end{abstract}

Palavras-chave: Geometria de Traços. Processos fonológicos. Síndrome de Down. Teoria Métrica da Sílaba.

\footnotetext{
*mdossoliveira@gmail.com

**vera.pacheco@gmail.com

**** portop91@gmail.com
} 
ABSTRACT: Down syndrome (DS) people exhibit peculiar physical and physiological characteristics as the ones related to his vocal tract: orofacial hypotony, macroglossia and small jaw. These aspects may make the voice of a DS person sound peculiar and sometimes with intelligibility problems. (Mustacchi \& Peres, 2000) These characteristics impair phonologicalphonetic performance. Considering the importance of this aspect for the communication, in this paper we present a study about the phonological processes (PPs) in the speech of people with SD. The analyzing was conducted by Geometry of Phonological Features by Clements \& Hume (1995) and by Metric Theory of the syllable (Selkirk,1982). We have as hypothesis: a) the changes and omissions found in their speech are phonological processes of substitution and syllabic structure; b) the phonological models mentioned can help us to understand the phonological processes (PPs) that can occur in the speech of these people. The data were collected with 12 individuals - Youngs and adults. Later we did the phonetic and phonological transcription of the speech data. The PPs were identified, cataloged and analyzed. The analysis shows that: i) two individuals presented only syllabical structure PPs and ten have presented substitution and syllabical structure PPs; ii) in their oral production there is a tendency to simplify more complex segments and syllable structures, like occurs during language acquisition period; iii) there is evidence of non-phonological specification of the characteristic value in the speech of some people.

Keywords: Down syndrome. Geometry of Phonological Features. Phonological processes. Metric Theory of Syllable.

\section{INTRODUÇÃO}

A síndrome de Down é considerada uma das mais comuns entre as alterações genéticas que comprometem o desenvolvimento global do indivíduo. Ao nascer com essa síndrome, a pessoa apresenta características fenotípicas peculiares, como: baixa estatura, hipotonia muscular generalizada, interna e externa, cavidade oral pequena ou macroglossia, maxila diminuída, macroglossia, língua fissurada, hipodontia, geminação, erupção e implantação dentária irregular e perda precoce, má oclusão e hipotonia (MUSTACCHI; PERES, 2000). Além disso, o indivíduo apresenta um déficit cognitivo; aquisição e desenvolvimento linguístico mais lentos. A fala do indivíduo com Down - criança, jovem ou adulto -, portanto, pode apresentar processos de trocas, omissões, apagamentos, entre outros, o que a torna de difícil compreensão.

$\mathrm{Na}$ presente pesquisa, propusemos apresentar um estudo sobre os processos fonológicos (PFs) na fala de pessoas com SD, à luz de dois modelos fonológicos não lineares. Para tanto, partimos dos seguintes questionamentos: a) Quais são os processos fonológicos mais comuns na fala de sujeitos com síndrome de Down que já passaram da fase de aquisição? b) De que modo os estudos fonológicos podem contribuir para a compreensão das dificuldades encontradas na fala do sujeito com $\mathrm{SD}$ ?

Diante disso, temos como hipóteses: a) as trocas e omissões encontradas na fala configuram processos fonológicos tanto de substituição quanto de estrutura silábica; e b) a Geometria de Traços, delineada por Clements (1985) e a Teoria Métrica da Sílaba, proposta em Selkirk (1982), podem auxiliar na compreensão de processos fonológicos que eventualmente ocorram na produção oral desses sujeitos. Como será abordado a seguir, esses são modelos teóricos que explicam as modificações dos traços fonológicos e alterações na estrutura silábica características dos PFs como os encontrados na fala dos sujeitos com SD por nós pesquisados. 
Salientamos: i) o acesso a pessoas com SD não é fácil, visto que essas pessoas, em sua maioria, não têm autonomia para, entre outras coisas, saírem sozinhas; ii) os dados desta pesquisa pertencem a um banco de dados (Banco de Dados Núcleo Saber Down - CNPq/MEC-UESB) que ainda está sendo organizado; iii) tentamos, na pesquisa, a partir do universo daquele Banco, levantar, em termos numéricos, um conjunto representativo de sujeitos; iv) não foi nossa pretensão controlar variáveis como sexo, idade e escolaridade, pois isso diminuiria significativamente o número de sujeitos pesquisados, e, embora tenhamos mencionado tais variáveis, podemos afirmar, sem sombra de dúvidas, que elas não condicionaram a ocorrência dos PFs, pois, em geral, todos os sujeitos apresentaram os mesmos processos, o que mostra que essas ocorrências estão muito mais relacionadas às características orgânicas dos sujeitos e não às sociais.

Assim, para apresentação desta pesquisa, este artigo está organizado em cinco itens: i) revisão sobre a produção oral na síndrome de Down; iii) o aporte teórico, em que expomos, em linhas gerais, considerações sobre processo fonológico e sobre os modelos teóricos da Geometria de Traços e da Teoria Métrica da sílaba; iv) os procedimentos metodológicos adotados; v) os resultados e a discussão dos dados encontrados; e por fim, vi) as conclusões.

\section{A PRODUÇÃo ORAL NA SÍNDROME DE DOWN}

O desenvolvimento da linguagem e da fala já se inicia nos primeiros meses de vida da criança. É nesse período que ela começa a conhecer e reconhecer os sons da sua língua e a tentar reproduzi-los de forma que, progressivamente, vai desenvolvendo seu aparelho fonador e estabelecendo, assim, a comunicação com os pais e as demais pessoas com quem convive. A criança com SD, em geral, apresenta essas mesmas características; no entanto o desenvolvimento da linguagem ocorre de forma mais lenta.

Além disso, a fala de pessoas com SD, em geral, é bastante peculiar, e isso pode estar relacionado a aspectos anatômicos ${ }^{1}$ comuns nas pessoas com essa síndrome, como: maxilar com crescimento menor, fenda palato ogival, macroglossia relativa com protusão ou pseudomacroglossia, em função do tamanho diminuído da cavidade oral, língua fissurada, doença periodontal, hipodontia ou oligodontia, geminação, fusão de dentes e microdontia, implantação irregular dos dentes, erupção atrasada, queda precoce dos dentes, incisivos centrais em meialua, incisivos laterais conoides, hipocalcificação, má oclusão dentária e hipotonia. (MUSTACCHI; PERES, 2000, MUSTACCHI; ROZONE, 1990).

\footnotetext{
${ }^{1}$ Ressaltamos que nem sempre todas essas características vão ser encontradas numa pessoa com síndrome de Down, de forma que algumas podem parecer mais salientes em umas que em outras - como é o caso da protusão da língua -, e isso pode ser amenizado, em parte, com a estimulação global, que promove o desenvolvimento pleno da pessoa com SD, no que diz respeito ao desempenho físico, linguagem e outros fatores relacionados à vida social.
} 
Todas essas peculiaridades comprometem a produção da fala, que depende da condição do trato vocal e do bom funcionamento dos articuladores, bem como de aspectos relacionados ao desenvolvimento cognitivo e social. Considerando que a língua é um dos articuladores ativos e tem papel fundamental na produção de segmentos importantes nas línguas naturais, a língua protusa compromete a precisão na produção dos sons da fala, assim como problemas nos articuladores passivos, como palato, alvéolos e dentes, impedem a realização bem-sucedida dos sons da língua, justamente no que se refere às características articulatórias dos segmentos.

As implicações das especificidades do trato vocal de pessoas com Down na fala foram discutidas por Hamilton (1993). A pesquisadora investigou os movimentos da língua na fala de três adultos com SD e um sem a síndrome falantes do inglês, por meio do eletropalatógrafo e técnicas diadococinéticas. ${ }^{2}$ Os resultados desse estudo mostraram que na produção dos segmentos alveolares $(/ \mathrm{t} /, / \mathrm{d} / \mathrm{e} / \mathrm{n} /)$, os sujeitos com SD usam mais a zona palatal e velar do que o sujeito sem a síndrome. Em relação à produção das oclusivas velares $(/ \mathrm{k} / \mathrm{e} / \mathrm{g} /)$, a autora afirma haver um posicionamento inadequado da língua na realização desses segmentos pelos sujeitos com $\mathrm{SD}$, sendo que dois deles tocam os alvéolos na realização das velares, o que não acontece na fala do sujeito sem Down.

Na produção da líquida /1/, Hamilton (1993) observou haver variabilidade e maior contato na região palatal e velar na realização desses segmentos pelos sujeitos com a síndrome. Nas fricativas /s/ e / $/$, observou também o aumento de contato na zona palatal. Além disso, a autora apresentou os processos fonológicos que envolveram as consoantes citadas na fala dos sujeitos com SD: apagamento da consoante final ("see" para seed), harmonia consonantal ("gog" para dog), anteriorização ("fis" para fish), plovização ("dot" para dolls) e redução de cluster ("bak" para black). Defende, a partir disso, que a imaturidade fonológica observada pode ser subproduto das limitações no movimento da língua e não evidências de atraso fonológico (HAMILTON,1993).

Kumin et al. (1994), em estudo sobre aquisição fonológica em crianças com síndrome de Down, examinaram registros clínicos de 60 crianças com SD para avaliação da aquisição de fonemas e suas ocorrências. Analisando dados de crianças com idade entre 9 meses e 9 anos, constataram que há uma variabilidade na aquisição fonológica dessas crianças e que a emergência dos sons não segue a ordem de aquisição da fala típica. Conforme as autoras, tal variabilidade e emergência atípica ocorrem porque a criança com SD apresenta hipotonia da musculatura orofacial, dificuldades na coordenação e no planejamento motor/a e atraso no desenvolvimento quando comparada com criança sem SD.

${ }^{2}$ Técnicas diadococinéticas são procedimentos que compreendem a repetição de determinada emissão sonora de forma rápida, com o objetivo de avaliar habilidades motoras orais. 
Cleland et. $\mathrm{Al}$ (2010) acreditam que o distúrbio da linguagem apresentado por pessoas com Down está relacionado com "[...] dificuldades na produção da fala, consequentes de deficiências no sistema responsável pela produção" (tradução nossa), ${ }^{3}$ tais como aspectos das características do trato vocal e funcionamento do aparelho fonador, como a hipotonia.

No entanto, Laws e Bishop (2004, apud CLELAND et al., 2010) consideram que as diferenças na anatomia e no funcionamento motor em si não contam para a gravidade do distúrbio da fala muitas vezes evidenciado em pessoas com SD, de forma que as diferenças encontradas na fala deles são consideradas resultados do atraso no desenvolvimento de habilidades fonológicas. Também é isso que propõem Roberts et al. (2005, apud CLELAND et al., 2010, p.84) que veem essas diferenças como "[...] consequência de atraso fonológico, de distúrbios da linguagem e de aspectos idiossincráticos no desenvolvimento linguístico dessas pessoas" [Tradução nossa]. ${ }^{4}$

Em recente revisão sobre pesquisas que abordaram/abordam o tema "desvio de fala e síndrome de Down", realizadas desde a década de 1950, vários estudos levantados por Kent e Vorperian (2013) comprovam que a inteligibilidade é um problema sério na SD que persiste durante toda a vida e pode ter efeitos negativos sobre atividades sociais e vocacionais e supõe-se que os distúrbios de voz, de articulação, de ressonância, de fluência e de prosódia contribuem para um déficit geral na inteligibilidade, ocorrência de trocas articulatórias entre outros. Nesses trabalhos é comum a associação entre os achados sobre a voz dos sujeitos pesquisados e as características do trato vocal deles, em especial, as alterações anatômicas e fisiológicas que apresentam.

Estudo da fala de brasileiros com SD, desenvolvido por Oliveira (2011), mostrou que aspectos do trato vocal desses sujeitos e a hipotonia comprometem a qualidade vocálica. A autora descreveu o padrão formântico das sete vogais do português em diferentes posições silábicas, produzidas por quatro sujeitos com SD, naturais de Vitória da Conquista, e contrastou com o padrão formântico das vogais produzida por quatro sujeitos sem SD, que apresentavam um perfil físico próximo ao dos sujeitos com $\mathrm{SD}$, e nascidos na mesma cidade. Todos foram submetidos à gravação do mesmo corpus, composto por 150 palavras.

A análise da autora sugere que as vogais produzidas pelos sujeitos com a síndrome possuem qualidades acústicas que as distinguem das produzidas pelos sujeitos sem SD e mostra que essa diferença se apresenta especialmente nos valores de F1 e F2, frequências formânticas que correspondem ao grau de abertura e posicionamento de língua na produção dos sons. Segundo Oliveira (2011), as peculiaridades acústico-articulatórias encontradas podem estar associadas à protusão da língua e à hipotonia da musculatura orofacial, características de pessoas com síndrome de Down.

${ }^{3}$ The speech disorder in DS is thought to result from impairments in almost all of the systems required for successful speech (CLELAND et al., 2010, p. 84).

${ }^{4}[\ldots]$ phonological delay with some elements of disorder, following an idiosyncratic developmental pattern, different from normal speakers (CLELAND et al., 2010, p.84) 
Como desdobramento dessa pesquisa, há os trabalhos realizados por Pereira, Oliveira e Pacheco (2012), Pereira et al. (2014) e Oliveira et al. (2015).

Pereira, Oliveira e Pacheco (2012), por sua vez, fizeram uma análise experimental da vogal /a/ em logatomas dissílabos produzidos por um sujeito com síndrome de Down e observaram que o F1, correlato de abertura vocálica, possui frequências maiores na posição pretônica e não na tônica - achado que confirma os resultados encontrados por Oliveira (2011).

Em pesquisa posterior de Pereira et al. (2014), as vogais altas do português foram inseridas em logatomas dissílabos formados com obstruintes, apresentados em frase veículos e foram lidas por três sujeitos com SD. Também nessa análise foram observados correlatos acústicos que corroboram as discussões anteriormente feitas com análise de vogais em contexto de palavras reais (OLIVEIRA, 2011, OLIVEIRA; PACHECO, 2012). A vogal /i/, por exemplo, apresentou valores de F2 que apontam para um grau de anterioridade maior na produção dessa vogal por dois dos sujeitos participantes, o que Pereira et al. (2014) relacionaram com a dificuldade que os sujeitos com SD apresentam em acomodar a língua no trato vocal.

Oliveira et al. (2015) explicaram como os correlatos acústicos encontrados na realização das vogais altas /i/ e /u/ e da vogal baixa /a/ podem dar pistas da articulação na produção desses segmentos, de forma a auxiliar terapeutas da fala - como fonoaudiólogos -, a desenvolverem terapias e exercícios que concorram para ajustar a trajetória articulatória na realização das vogais por indivíduos com SD.

Em Oliveira e Pacheco (2016), as autoras fazem uma relação entre os achados acústicos e sua implicação no componente fonológico, a partir da Geometria de Traços - uma das teorias das quais lançamos mão em nossas análises. Nessa pesquisa, Oliveira e Pacheco (2016) procuraram responder se a diferença fonética percebida na fala de pessoas com síndrome de Down - como constatado em trabalhos anteriormente citados - teriam implicações para o sistema linguístico. Para tanto, as autoras analisaram as médias das frequências formânticas F1 e F2 das vogais do português realizadas por sujeitos com e sem Down, apresentadas em gráficos de dispersão, gerados no programa Praat (BOERSMA; WEENINK, 2006). Com esses gráficos, as autoras puderam mostrar as zonas espectrais das vogais em diferentes posições silábicas e trazer evidência sobre a marcação do contraste fonológico na produção de vogais pelos sujeitos com Down.

Conforme a Geometria de Traços, o contraste entre as vogais é marcado, na estrutura interna, pelos traços ligados ao ponto de V: [labial], [coronal] e [dorsal], e os traços do nó de abertura: [ \pm Alto, \pm Baixo, \pm ATR] (MATZENAUER; MIRANDA, 2009, apud OLIVEIRA; PACHECO, 2016). Considerando esses elementos e as análises das dispersões vocálicas, elas constataram que os sujeitos com SD preservam os contrastes entre [coronal] e [dorsal] e entre [+baixo] e [-baixo +Alto, +ATR2], que evidenciam o contraste de ponto e de abertura, que são oposições essenciais no sistema vocálico do português. Porém, o contraste não foi percebido entre [-Bx,+Alto, +ATR] e [-Bx,-Alto, +ATR], bem como, entre [-Bx,-Alto, +ATR] e [-Bx, -Alto, -ATR] na sílaba tônica, o que compromete a realização de segmentos como [i, e, E] e dos segmentos [u, o, ç] (OLIVEIRA; PACHECO, 2016). 
Conforme explicitado pelas autoras, a diferença na articulação dessas vogais é muito pequena; o sujeito com SD, por causa de suas características anatômicas, apresenta dificuldade em manter a distinção entre elas na produção oral. Apesar disso, segundo as pesquisadoras, os contrastes que demonstram diferenças extremas permanecem, de forma que a comunicação da pessoa com SD não é completamente comprometida (OLIVEIRA; PACHECO, 2016).

Diante do exposto e com base nas autoras, podemos afirmar que as características do trato vocal da pessoa com SD e a hipotonia generalizada que apresenta têm implicação direta na produção oral. Podemos considerar isso como um fator diretamente relacionado com as peculiaridades da fala desses indivíduos, especialmente as ocorrências de processos fonológicos, alvo das discussões da pesquisa por nós realizada. Também fica evidente a robustez do modelo da Geometria de traços na evidenciação da relação entre características do trato vocal e das alterações de fala apresentadas pela pessoa com Down, o que já justificaria a replicação do modelo à análise fonológica de dados de natureza segmental dessa população.

Assim, apresentamos no item seguinte considerações sobre os processos fonológicos à luz dos modelos teóricos utilizados neste estudo.

\section{PROCESSOS FONOLÓGICOS E OS MODELOS TEÓRICOS DA GEOMETRIA DE TRAÇOS E TEORIA MÉTRICA DA SÍLABA}

O processo fonológico é definido por Stampe (1973) como uma operação mental aplicada à fala, que busca maximizar características perceptuais da fala $\mathrm{e}$ minimizar dificuldades articulatórias, ou seja, o PF levará sempre à simplificação da fala, mas sem eliminar aspectos essenciais à percepção e à compreensão.

Os processos fonológicos são fenômenos naturais da língua, isto é, eles participam do funcionamento do sistema fonológico e são reconhecidos em diferentes contextos. Podem ser considerados pelo ponto de vista sincrônico - que são aqueles que integram o sistema fonológico de uma determinada língua; ou pelo ponto de vista diacrônico - aqueles que estão envolvidos nas transformações que aconteceram e acontecem nas línguas no decorrer do tempo. Além disso, os processos apresentam-se em excesso em todas as línguas, na fala infantil, no período em que o sistema fonológico está sendo adquirido.

Para a compreensão desses processos, tomamos como base teórica a Geometria de Traços (CLEMENTS; HUME, 1995) e a Teoria Métrica da Sílaba (SELKIRK, 1982), ambos modelos não-lineares, isto é, teorias que consideram que o componente sonoro das língua seja constituído por camadas. O primeiro propõe que os segmentos das línguas sejam constituídos por camadas organizadas hierarquicamente nas quais são acomodados os traços fonológicos. O segundo se concentra na organização interna dos constituintes silábicos.

No que se refere à Geometria de Traços, podemos afirmar que a primeira proposta do modelo é apresentada por Clements (1985), no artigo The Geometry of Phonological Features. No decorrer dos dez anos seguintes, outras versões foram desenvolvidas até chegar ao modelo apresentado em The internal organization of speech sounds (CLEMENTS; HUME, 1995). 
Em 1995, Clements e Hume propõem uma arquitetura de organização interna das consoantes e vogais, conforme apresentado na figural.

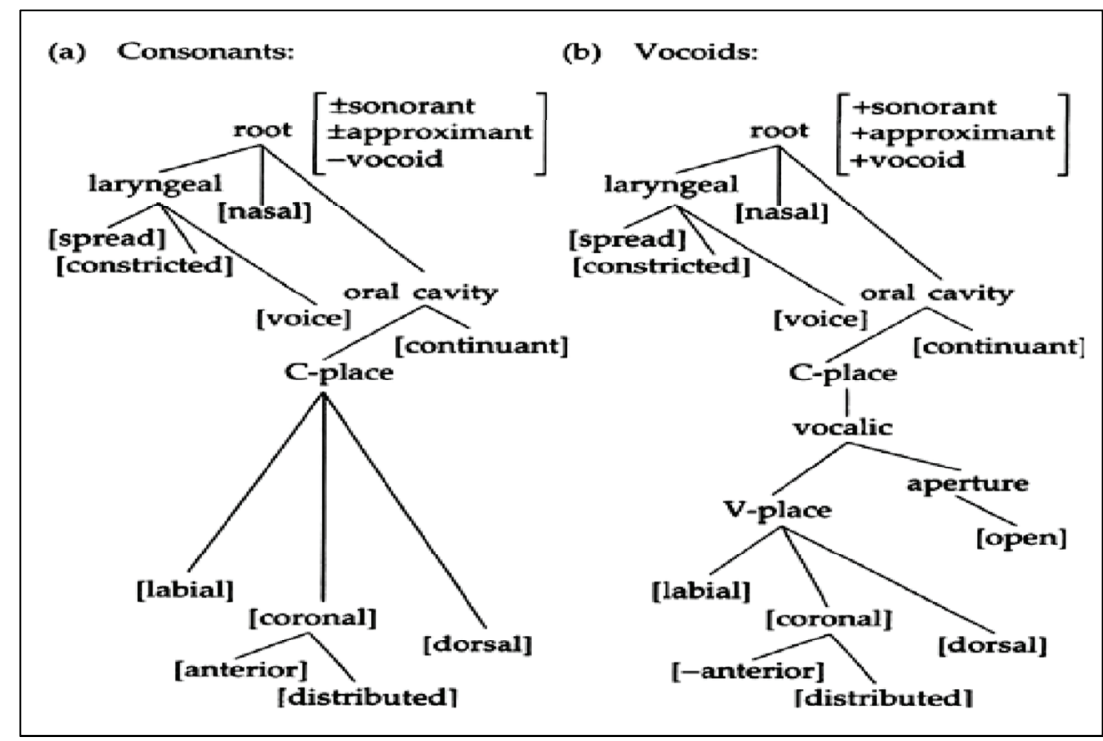

Figura 1: Representação arbórea da consoante e da vogal apresentado por Clements e Hume (1995).

Fonte: Clements e Hume (1995, p.292).

De acordo com essa proposta, tanto consoantes como vogais são representadas com uma organização interna e podem ser visualizadas através de configurações de nós hierarquicamente organizados, em que, segundo Matzenauer e Miranda (2009), os nós terminais são traços fonológicos e os nós intermediários, classes de traços.

A lógica subjacente na organização desses nós é a própria articulação dos sons, tendo por base a configuração do traço vocal compreendido da laringe aos lábios. Hierarquicamente, estão no mesmo nível de hierarquia a participação das pregas vocais, representada pelo nó laríngeo e o modo e ponto de articulação, representado pelo nó cavidade oral. Assim, a Geometria de Traços integra em uma mesma proposta aspectos fonéticos e fonológicos na investigação do componente sonoro da língua e torna explicita dessa forma, a inter-relação entre a produção do som e a organização sonora da língua.

É o fato de integrar a fonética e a fonologia que torna a Geometria de Traços o modelo mais adequado para avaliar a produção oral de sujeitos com SD, uma vez que essa síndrome possui entre as suas principais características alterações marcantes no trato vocal, como já foi apresentado. A partir desse modelo, podemos avaliar as implicações das especificidades do trato vocal dos sujeitos com Down em suas produções orais e que consequências essas produções orais trazem para a sua fonologia. Ademais, a unidade fonológica privilegiada nesse modelo é o segmento, unidade alvo dos PFs recorrentemente encontrados na fala dos sujeitos com SD. 
Além disso, por meio da Geometria de Traços (CLEMENTS, 1985, CLEMENTS; HUME, 1995), é possível explicar mais claramente a naturalidade dos processos fonológicos. Conforme Clements e Humes (1995), os processos ocorrem segundo dois princípios:

i) o primeiro diz respeito ao fato de que as regras fonológicas constituem uma única operação; por isso elas só podem ocorrer com um conjunto de traços que compartilham o mesmo nó de classe. Quando um processo fonológico recai sobre um nó, todos os elementos dominados por ele são também afetados. Assim, caso um processo atinja o ponto de $\mathrm{C}$, por exemplo, haverá mudança em toda a articulação do segmento. Esse princípio mostra que somente traços que pertencem à mesma classe podem funcionar juntos numa regra fonológica.

ii) o segundo princípio diz que a organização dos traços é universal, o que justifica o fato de as regras fonológicas serem comuns às várias línguas.

A Geometria de Traços pode, pois, evidenciar as alterações segmentais na fala dos sujeitos com SD decorrentes das características de seu aparelho fonador e as consequências dessas alterações na fonologia

Considerando que a fala dos sujeitos com SD apresenta alterações segmentais que têm implicações diretas na constituição e organização da sílaba e que a unidade de investigação da Geometria de Traços é o segmento, PFs que afetam a estruturação silábica não são descritos e explicados pela Geometria de Traços. Assim, é notória a necessidade de lançar mão de um modelo teórico não linear cuja unidade de investigação seja a sílaba e que integre igualmente a fonética e a fonologia. Tendo em vista essas balizas, o modelo mais adequado é o modelo de sílaba proposto por Selkirk (1982) no escopo da Teoria Métrica.

De acordo com Selkirk (1982), a sílaba é formada por elementos hierarquicamente organizados: um ataque (A) e uma rima (R); a rima, por sua vez, consiste em um núcleo $(\mathrm{N})$ e uma coda $(\mathrm{C})$. Com exceção do $\mathrm{N}$, as demais categorias podem não ser preenchidas.

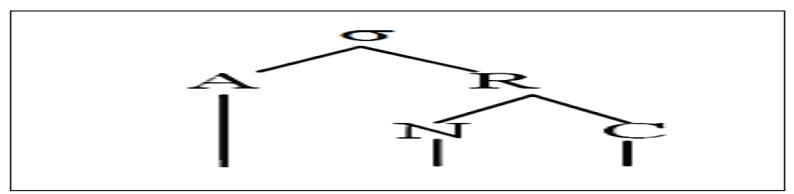

Figura 2: Representação da sílaba baseada em Selkirk (1982).

Fonte: Elaboração própria.

Através da representação arbórea da Teoria Métrica da Sílaba, é possível apresentar as características gerais da sílaba de uma língua através de um template (ou modelo). Conforme Selkirk (1982), a sílaba será bem formada se tiver de acordo com o template da sílaba da língua.

De acordo com o template de sílaba do $\mathrm{PB}$, as posições de ataque e coda são ocupadas por consoantes e a posição de núcleo é ocupada por vogais. 
Ao prever quais segmentos podem ocupar cada um dos constituintes silábicos, o modelo de sílaba de Selkirk (1982) é eficaz para estabelecer a relação entre a forma como o segmento é ou não produzido e qual impacto dessa produção na organização hierárquica da sílaba, o que é fundamental na investigação da fala de sujeitos afetados por uma síndrome que compromete significativamente a produção oral dos sujeitos como é o caso da SD.

Dessa forma, com base nesse modelo e na Geometria de Traços, apresentamos o estudo feito da produção oral de 12 sujeitos com síndrome de Down. Os procedimentos metodológicos para o desenvolvimento desta pesquisa são apresentados a seguir.

\section{PROCEDIMENTOS METODOLÓGICOS}

Este artigo é um recorte da dissertação de mestrado de Souza $(2017)^{5}$ que traçou uma investigação sobre os processos fonológicos que ocorrem na fala e na escrita de sujeitos com síndrome de Down.

Para a realização das análises, foram realizadas buscas em gravações de vídeos e áudios, do Banco de Dados do Núcleo de Pesquisas e Estudos em Síndrome de Down - Saber Down (CNPq/ MEC/UESB). ${ }^{6}$

Construímos um corpus formado por dados de nomeação espontânea (05 gravações em vídeos e 03 gravações em áudio) e de fala espontânea (11 vídeos de atendimento do núcleo), homens e mulheres, de variadas idades, sem escolarização, em alfabetização e alfabetizados, pois esse era o universo disponível no Banco. (Quadro 1)

Quadro 01: Identificação e estratificação social dos sujeitos da pesquisa.

\begin{tabular}{|l|l|l|l|}
\hline IDENTIFICAÇÃO & SEXO & IDADE & \multicolumn{1}{|c|}{ ESCOLARIDADE } \\
\hline LSF1 & Feminino & 18 & Alfabetizada \\
\hline NSF2 & Feminino & 18 & Alfabetizada \\
\hline TSF3 & Feminino & 22 & Analfabeta \\
\hline ESF4 & Feminino & 14 & Em alfabetização \\
\hline ASM5 & Masculino & 35 & Alfabetizado \\
\hline CSM6 & Masculino & 28 & Analfabeto \\
\hline FSM7 & Masculino & 24 & Analfabeto \\
\hline JSM8 & Masculino & 15 & Analfabeto \\
\hline
\end{tabular}

\footnotetext{
${ }^{5}$ Processos fonológicos na fala e na escrita de sujeitos com síndrome de Down: uma interpretação via Geometria de Traços e Teoria Métrica da Sílaba (SOUZA, 2017), pesquisa aprovada pelo Conselho e Ética: CAAE 04853012.6.0000.0055).

${ }^{6} \mathrm{O}$ Saber Down é um projeto de pesquisa que desenvolve várias atividades, dentre elas um conjunto de atividades voltadas à estimulação global do indivíduo com SD.
} 


\begin{tabular}{|l|l|l|l|}
\hline KSM9 & Masculino & 15 & Em alfabetização \\
\hline MSM10 & Masculino & 18 & Analfabeto \\
\hline PSM11(SM5) & Masculino & 28 & Analfabeto \\
\hline VSM12 & Masculino & 30 & Analfabeto \\
\hline
\end{tabular}

Chave de Leitura do Quadro 1: Primeira letra maiúscula: Letra de nome fictício adotado no Banco; S: Sujeito; F: Feminino; M: Masculino; Número: Número do sujeito.

Fonte: Elaboração própria.

Os sujeitos nomearam cerca de 110 (cento e dez) imagens que correspondem a palavras com diferentes fonemas e configurações silábicas, incluindo nomes de animais, objetos e frutas (em algumas gravações, a quantidade de palavras apresentadas foi reduzida, ocorrendo a nomeação de cerca de 90 (noventa) palavras).

O critério que orientou a seleção desses vídeos e áudios foi o de se ter um corpus de nomeação e fala espontânea que apresentasse, o máximo possível, as diferentes possibilidades de organização do sistema do português brasileiro silábicas, fonotáticas. Dessa forma, o corpus apresentava os fonemas do português nas configurações silábicas seguintes: V, CV, VC, CVC, CVV, CCV, CCVC. Nas nomeações analisadas, foram encontradas cerca de 185 (cento e oitenta e cinco) ocorrências de processos fonológicos.

Na coleta dos vídeos de fala espontânea, apuramos cerca de 55 ocorrências de processos fonológicos nas produções orais dos sujeitos. Salientamos que o atendimento do núcleo consiste em atividades de estímulo das habilidades linguísticas. Dessa forma, identificamos as palavras que apresentavam processos fonológicos entre as conversas, momento de expressão oral, encontradas nas gravações do atendimento no projeto. Em síntese, tivemos 185 dados de nomeação e 55 de fala espontânea, totalizando 240 ocorrências de processos fonológicos, como podemos observar na tabela 1:

Tabela 1: Síntese da coleta de dados de fala.

\begin{tabular}{c|c|c|c}
\hline Atividade & Vídeos & Áudios & No. De Co-ocorrências de PFs ${ }^{7}$ \\
\hline Nomeação Espontânea & 05 & 03 & 185 \\
\hline Fala Espontânea & 11 & - & 55 \\
\hline TOTAIS & 16 & 03 & 240 \\
\hline
\end{tabular}

Fonte: elaboração própria.

${ }^{7}$ Foram considerados para este estudo apenas as produções que apontavam para processos incomuns para idade e que não tinham relação com aspectos dialetais dos sujeitos participantes. 
As ocorrências dos PFs encontrados foram listadas em quadros, organizados por sujeito. Neles constaram a palavra alvo, seguida das transcrições fonológica e fonética e a classificação do processo correspondente. Salientamos que as transcrições fonéticas foram feitas a partir da análise de oitiva. Para sabermos da recorrência de cada processo por indivíduo, montamos um quadro com todas as ocorrências de cada processo. Em seguida, foram feitas as análises dos processos com base na Geometria de Traços e na Teoria Métrica da Sílaba.

\section{RESULTADOS E DISCUSSÃO}

Diante das análises dos dados de produção oral (dados do corpus formado por nomeação e fala espontânea) de 12 sujeitos com SD de idade entre 14 a 30 anos, pudemos identificar 21 processos fonológicos. Foram 14 processos de substituição: lateralização, rotacismo, sonorização, dessonorização, nasalização, plosivização, africação, anteriorização, semivocalização, substituição do /¥/ pelo /1/, posteriorização, alteamento, abaixamento e labialização; e 7 processos de estrutura silábica: apagamento de sílaba átona, apagamento de coda, monotongação, apagamento de cluster, apagamento de ataque, metátese e inserção.

Apesar de encontrarmos essa variedade de PFs, ressaltamos que eles não foram identificados na fala de todos os sujeitos, isto é, houve PFs que apareceram nos dados de alguns e de outros não. No quadro abaixo, expomos a quantidade de processos encontrados na fala de cada sujeito.

Tabela 02: PFs encontrados na produção oral dos sujeitos com SD.

\begin{tabular}{c|l|l|c}
\hline Sujeitos & PFs de substituição & PFs de estrutura silábica & Total de PFs \\
\hline LSF1 & $\begin{array}{l}\text { Dessonorização, } \\
\text { nasalização, } \\
\text { lateralização, rotacismos, } \\
\text { semivocalização, } \\
\text { alteamento. }\end{array}$ & $\begin{array}{l}\text { Apagamento de sílaba átona, } \\
\text { apagamento de coda, } \\
\text { metátese, }\end{array}$ & 9 \\
\hline NSF2 & $\begin{array}{l}\text { Sonorização, } \\
\text { dessonorização, } \\
\text { nasalização, } \\
\text { posteriorização } \\
\text { rotacismos, africação, } \\
\text { semivocalização, } \\
\text { abaixamento }\end{array}$ & $\begin{array}{l}\text { Apagamento de sílaba } \\
\text { átona, apagamento de } \\
\text { coda, redução de cluster, } \\
\text { monotongação. }\end{array}$ & 12 \\
\hline ESF4 & $\begin{array}{l}\text { Dessonorização, } \\
\text { posteriorização, } \\
\text { lateralização, rotacismo, }\end{array}$ & $\begin{array}{l}\text { Apagamento de sílaba } \\
\text { átona, apagamento de } \\
\text { coda, redução de cluster, } \\
\text { apagamento de ataque. }\end{array}$ & 8 \\
\hline
\end{tabular}




\begin{tabular}{|c|c|c|c|}
\hline ASM5 & $\begin{array}{l}\text { Sonorização, } \\
\text { nasalização, } \\
\text { africação, rotacismo, } \\
\text { semivocalização, } \\
\text { alteamento, } \\
\text { abaixamento, } \\
\text { labialização. }\end{array}$ & $\begin{array}{l}\text { Apagamento de sílaba } \\
\text { átona, apagamento de } \\
\text { coda, redução de cluster, } \\
\text { apagamento de ataque. }\end{array}$ & 12 \\
\hline CSM6 & $\begin{array}{l}\text { Plosivização, } \\
\text { lateralização, } \\
\text { semivocalização, } \\
\text { alteamento, } \\
\text { abaixamento, inserção. }\end{array}$ & $\begin{array}{l}\text { Apagamento de coda, } \\
\text { redução de cluster, } \\
\text { monotongação. }\end{array}$ & 9 \\
\hline FSM7 & $\begin{array}{l}\text { Sonorização, } \\
\text { nasalização, africação, } \\
\text { anteriorização, } \\
\text { posteriorização, } \\
\text { rotacismos, } \\
\text { semivocalização, } \\
\text { alteamento, } \\
\text { abaixamento. }\end{array}$ & $\begin{array}{l}\text { Apagamento de sílaba } \\
\text { átona, redução de } \\
\text { cluster, monotongação, } \\
\text { apagamento de ataque, } \\
\text { inserção. }\end{array}$ & 14 \\
\hline JSM8 & $\begin{array}{l}\text { Sonorização, } \\
\text { dessonorização, } \\
\text { nasalização, } \\
\text { posteriorização, } \\
\text { lateralização, troca do } \\
\text { // pelo /1/, altamento, } \\
\text { abaixamento. }\end{array}$ & $\begin{array}{l}\text { Apagamento de sílaba } \\
\text { átona, apagamento } \\
\text { de coda, redução de } \\
\text { cluster, monotongação, } \\
\text { apagamento de ataque, } \\
\text { inserção. }\end{array}$ & 14 \\
\hline KSM9 & $\begin{array}{l}\text { Sonorização, } \\
\text { lateralização, } \\
\text { semivocalização, } \\
\text { alteamento. }\end{array}$ & $\begin{array}{l}\text { Apagamento de sílaba } \\
\text { átona, apagamento } \\
\text { de coda, redução de } \\
\text { cluster, monotongação, } \\
\text { apagamento de ataque, } \\
\text { inserção. }\end{array}$ & 11 \\
\hline MSM10 & Semivocalização & $\begin{array}{l}\text { Apagamento de sílaba } \\
\text { átona, apagamento de } \\
\text { coda, redução de cluster, } \\
\text { apagamento de ataque. }\end{array}$ & 5 \\
\hline MSM11 & $\begin{array}{l}\text { Nasalização, } \\
\text { africação,anteriorização, } \\
\text { posteriorização, } \\
\text { lateralização, rotacismo, } \\
\text { troca do } ¥ / \text { pelo /1/. }\end{array}$ & $\begin{array}{l}\text { Apagamento de sílaba } \\
\text { átona, apagamento } \\
\text { de coda, redução de } \\
\text { cluster, monotongação, } \\
\text { apagamento de ataque, } \\
\text { metátese }\end{array}$ & 13 \\
\hline VSM12 & --- & $\begin{array}{l}\text { Apagamento de coda, } \\
\text { redução de cluster, } \\
\text { monotongação. }\end{array}$ & 3 \\
\hline
\end{tabular}

Fonte: elaboração própria. 
Por meio das análises, é possível perceber que na produção oral dos sujeitos analisados a estrutura interna dos segmentos e das sílabas é afetada, como podemos observar nos resultados que serão abordados nos próximos itens.

\subsection{Análise dos processos de substituição}

Os processos de substituição são aqueles que resultam em troca entre segmentos. Com base na teoria não-linear da Geometria de Traços, é possível compreender que tais substituições estão relacionadas a modificações na estrutura interna dos segmentos, isto é, são resultados de (não) marcação ou queda de traços (ou nó), ou mesmo, espraiamento de traços de segmentos adjacentes. Portanto, por meio desse modelo fonológico, podemos identificar os traços e nós envolvidos na realização dos processos.

Para melhor explicarmos os PFs encontrados, apresentamos, nas figuras abaixo, a representação arbórea dos traços que compõem as consoantes do português e a representação proposta por Souza (2017) para explicar os processos de substituição encontrados na fala de pessoas com SD.

Na proposta de Souza (2017), as linhas pontilhadas indicam os traços envolvidos nos PFs encontrados na produção dos sujeitos com SD. Portanto, se compararmos as duas representações (Figuras 3 e 4), podemos perceber que há, na produção de sujeitos com $\mathrm{SD}$, o comprometimento de todos os traços terminais: o traço [sonoro] - que diz respeito à articulação das pregas vocais; os traços ligados ao nó ponto de $\mathrm{C}$ - relacionados à articulação na cavidade oral; e o traço [contínuo] - relacionado à constrição do trato vocal, além dos traços [nasal] e [lateral].

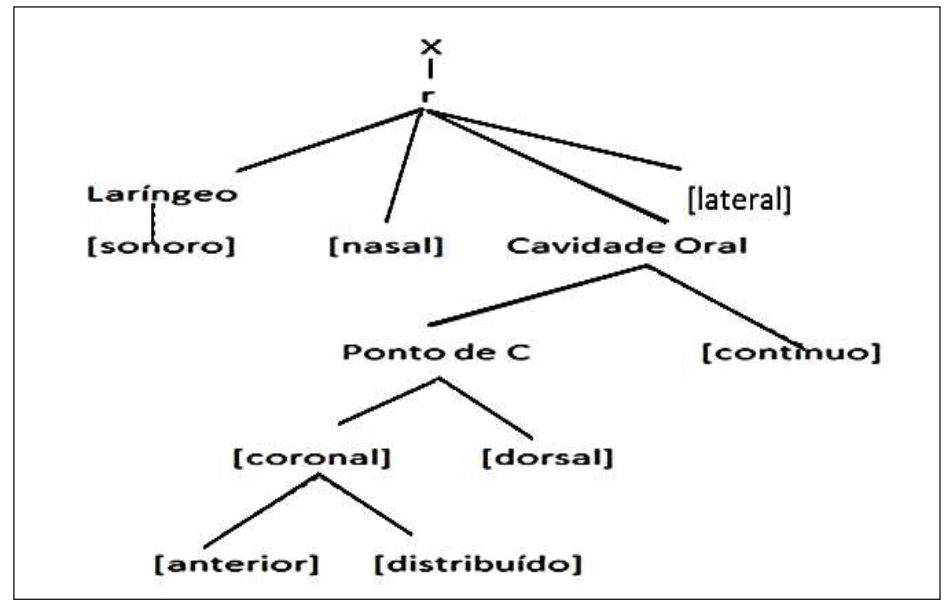

Figura 3: Representação dos traços que compõem as consoantes do português.

Fonte: Elaboração própria. 


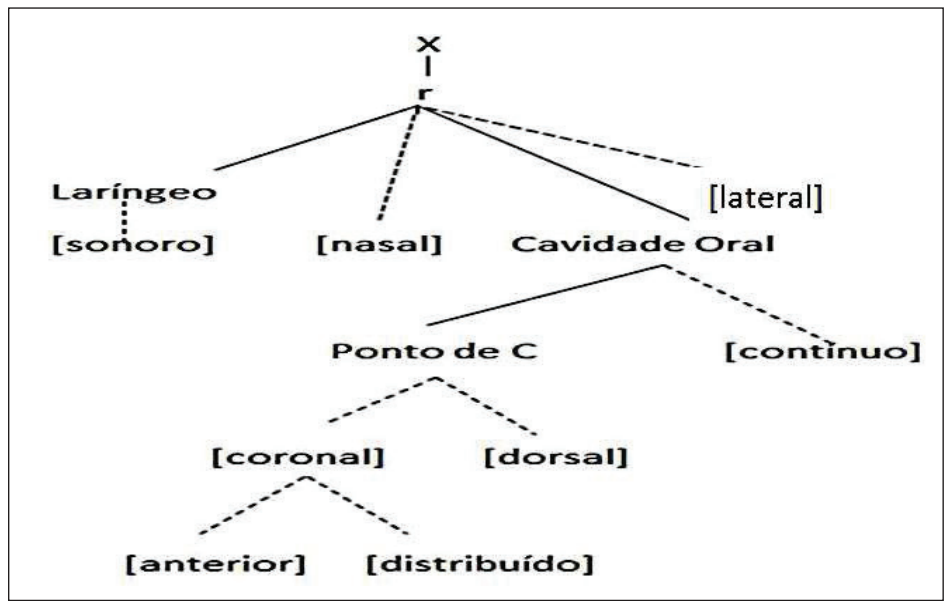

Figura 4: Interpretação dos PFs na produção das consoantes de sujeitos com SD (SOUZA, 2017).

Fonte: Elaboração própria.

No quadro 3, expomos os processos resultantes da modificação de cada um desses traço, seja por desligamento, ligamento ou assimilação.

Quadro2:Traços envolvidos nos PFs encontrados na produção oral dos sujeitos com SD.

\begin{tabular}{|c|c|c|}
\hline Traços terminais & Processos fonológicos & Alterações/exemplos \\
\hline \multirow{2}{*}{ [sonoro] } & Sonorização & $/$ pi»kena/ $\rightarrow[$ bi'ke nå] \\
\hline & Dessonorização & $\mid$ ga $\left.\gg l i^{-} \mathrm{a} / \rightarrow[\mathrm{ka}\rangle l \mathrm{l}^{-} \mathrm{a}\right]$ \\
\hline [labial] & Labialização & /se»bola/ $\rightarrow$ [so»bolå] \\
\hline [coronal] [dorsal] & Posteriorização & $/$ to» $/$ mati $/ \rightarrow[$ ko»matI $]$ \\
\hline [distribuído] [anterior] & Anteriorização & /a»goRa/ $\rightarrow$ [a»golå] \\
\hline \multirow{2}{*}{ [lateral] } & Lateralização & $/ \gg f l o R / \rightarrow[» f R o]$ \\
\hline & Rotacismo & $/ \mathrm{va} » \mathrm{ki}^{-} \mathrm{a} / \rightarrow\left[\mathrm{ba} » \mathrm{ki}^{-} \mathrm{a}\right]$ \\
\hline \multirow{2}{*}{ [contínuo] } & Plosivização & $/ \mathrm{Zi}^{\prime}$ rafa$/ \rightarrow[$ tSi»Rafå $]$ \\
\hline & Africação & $/ 3 i^{\prime}$ rafa/ $\rightarrow[\mathrm{tSi} \gg$ Rafå $]$ \\
\hline \multirow{2}{*}{ [abertura] } & Alteamento & $/$ to»mati/ $\rightarrow[$ tI»matI $]$ \\
\hline & Abaixamento & $/$ pe»teka/ $\rightarrow[$ på)»tEkå] \\
\hline [nasal] & Nasalização & $/$ laRaNZa/ $\rightarrow$ [na»rãze $]$ \\
\hline
\end{tabular}

Fonte: Elaboração própria. 
Além desses processos relacionados aos traços terminais, houve um processo que originou-se do desligamento de um nó, que é o caso da substituição do /\#/ pelo $/ 1 /(/(/>i ¥ a /[\gg i l a ̊])$, em que o nó vocálico é desligado.

Em relação aos processos ocorridos em vogais, estão envolvidos os traços de ponto de $\mathrm{V}$ e os traços de abertura, como mostra a figura 5, também uma proposta de Souza (2017) para representar os traços envolvidos nos processos de substituição na produção das vogais. Entre os traços, destacamos o [ $\left.{ }_{\mathrm{ab}} 2\right]$ como um dos principais responsáveis pelos processos de alteamento e abaixamento.

Os processos nas vogais também podem estar intimamente relacionados às características do trato vocal dos sujeitos, pois, apesar de as vogais serem consideradas segmentos de articulação mais simples, exigem um controle articulatório preciso como afirmam Oliveira (2011) e Oliveira e Pacheco (2016). Observamos também que alguns casos foram resultados de processo assimilatório, o que não deixa de confirmar a dificuldade desses sujeitos no gerenciamento e estruturação dos traços na cadeia da fala.

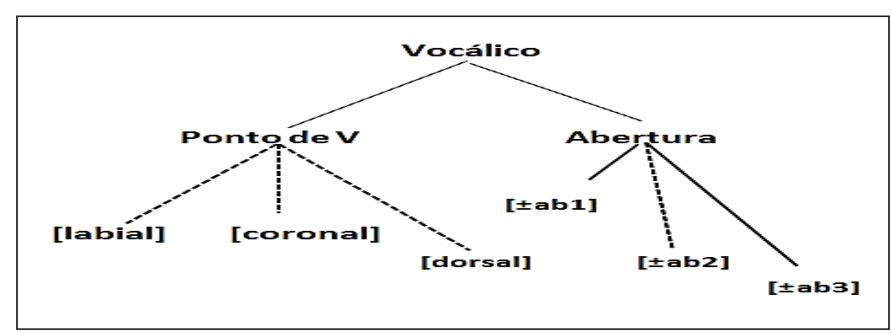

Figura 5: Proposta de interpretação dos PFs envolvidos nos processos fonológicos encontrados na produção das vogais de pessoas com SD (SOUZA, 2017)

Fonte: Elaboração própria.

A dificuldade na estruturação dos traços revela que os processos encontrados apresentam uma motivação fonética, isto é, estão relacionados principalmente à dificuldade na produção. Contudo, apontam uma implicação fonológica, tendo em vista que interferem em questões distintivas.

Os processos em que envolvem os traços ligados ao ponto de $\mathrm{C}$ e o traço [contínuo] podem estar associados à hipotonia, como também à macroglossia, tão comum entre os sujeitos com SD. Como principal articulador ativo, a língua, não bem posicionada, propicia os vários processos de substituição observados na análise dos dados da pesquisa.

\subsection{Processos de estrutura silábica}

Os processos fonológicos de estrutura silábica são aqueles que resultam em modificações na estrutura de sílabas na palavra. As análises apontaram que os processos encontrados, em sua maioria, apontam a tendência, por parte dos sujeitos, à simplificação da sílaba, pois a maioria dos processos reduz sílabas mais complexas, resultando, especialmente, na estrutura silábica priorizada da língua: $\mathrm{CV}$. 
Quadro3: Processos de estrutura silábica encontrados na fala de sujeitos com síndrome de Down.

\begin{tabular}{|c|c|c|c|}
\hline $\begin{array}{l}\text { Processo } \\
\text { fonológico }\end{array}$ & $\begin{array}{l}\text { Estrutura(s) } \\
\text { silábica(s) } \\
\text { modificada(s) }\end{array}$ & $\begin{array}{l}\text { Estrutura silábica } \\
\text { resultante }\end{array}$ & Exemplos \\
\hline $\begin{array}{l}\text { Apagamento de } \\
\text { sílaba átona }^{8}\end{array}$ & $\begin{array}{l}\text { CV.CV.CV } \\
\text { V.CV.CV } \\
\text { V.CV.CVC }\end{array}$ & $\begin{array}{l}\text { CV.CCV } \\
\text { CV.CV } \\
\text { CV.CVC }\end{array}$ & $\begin{array}{l}\text { /»silaba/ } \rightarrow[\text { [sibRå }] \\
\text { /aba»kati/ } \rightarrow[\text { ba»katSI }] \\
/ \text { /»onibuS/ } \rightarrow[\text { õous }]\end{array}$ \\
\hline $\begin{array}{l}\text { Apagamento } \\
\text { de coda }\end{array}$ & $\mathrm{CVC}$ & $\mathrm{CV}$ & $/$ veR»me $¥ a / \rightarrow[$ ve'me $K \mathrm{e}]$ \\
\hline Monotongação & CVV & $\mathrm{CV}$ & $/$ pa»lasiu/ $\rightarrow$ [pa»las $]$ \\
\hline $\begin{array}{l}\text { Apagamento } \\
\text { de cluster }\end{array}$ & $\mathrm{CCV}$ & $\mathrm{CV}$ & $/ » \operatorname{livRu} / \rightarrow[» \operatorname{liv} v]$ \\
\hline $\begin{array}{l}\text { Apagamento } \\
\text { de ataque }\end{array}$ & $\mathrm{CV}$ & V & $/$ pa»¥asu/ $\rightarrow[$ pa»asU] \\
\hline Metátese & $\begin{array}{l}\mathrm{CVC} \\
\mathrm{CV} \\
\mathrm{CVC}\end{array}$ & $\begin{array}{l}\mathrm{CCV} \\
\mathrm{VC} \\
\mathrm{CVC}\end{array}$ & $\begin{array}{l}\text { /iNpoR»taNti/ } \rightarrow[\text { i)pro»tå)tI }] \\
\text { sa»patu/ } \rightarrow[\text { as»patU }] \\
/ \text { boRbo»leta/ } \rightarrow[\text { boboh»letå }]\end{array}$ \\
\hline Inserção & V & $\mathrm{CV}$ & $/$ ele»faNti/ $\rightarrow[$ tEle»fãtSI $]$ \\
\hline
\end{tabular}

Fonte: Elaboração própria.

Como observamos no quadro acima, os processos que não resultaram em simplificação de sílabas foram o apagamento de sílaba átona e a metátese. No caso do primeiro, houve a redução do tamanho da palavra. Esse comportamento pode ser explicado, segundo Collischonn (2007), como resultado da tendência da língua de buscar o acento menos marcado, que, no caso do português, é o acento paroxítono. Como observado pela autora, nesses casos há uma disputa entre duas forças: a estrutura do acento e a estrutura silábica. A estrutura do acento busca diminuir o número de sílabas e a estrutura da sílaba busca evitar constituições complexas; nos casos encontrados, vence a estrutura do acento. Esse fenômeno foi observado na produção [»sibRå], em que a palavra proparoxítona /»silaba/ é reduzida a uma palavra paroxítona (Quadro 3).

Em relação à metátese, observamos que esse processo aponta uma dificuldade na organização da sequência dos segmentos da palavra e isso pode ser relacionado à dificuldade de ordem de planejamento.

\footnotetext{
${ }^{8} \mathrm{O}$ processo fonológico de apagamento de sílaba átona não busca a simplificação da sílaba, mas implica, sobretudo, na redução do tamanho da palavra. Contudo, esta mudança na palavra pode resultar em estruturas silábicas novas, isto é, em estruturas que não compunham a palavra alvo, como mostra os exemplos no quadro 4.
} 
Entre os PFs de estrutura silábica encontrados, os que apareceram numa quantidade maior de sujeitos foram: redução de cluster e apagamento de coda, ambos identificados em 10 (dez) dos 12 (doze) sujeitos investigados. As representações da figura 3 mostram as modificações ocorridas dentro da estrutura da sílaba resultantes desses dois processos.

Com base na Teoria Métrica da Sílaba, podemos afirmar que o processo de redução de cluster resulta na queda da segunda posição do ataque; assim como no apagamento da coda, há a queda da coda da sílaba. Ambos são elementos que compõem estruturas consideradas sílabas complexas.

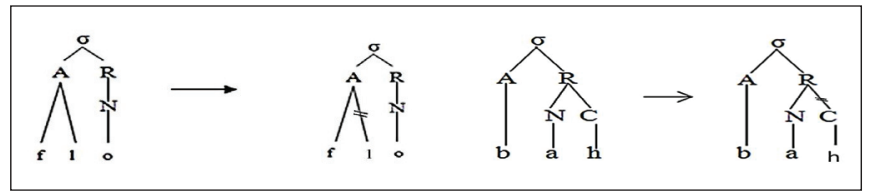

Figura 6 - Proposta de interpretação da simplificação silábica complexas em PFs de redução de cluster e apagamento de coda na fala de sujeitos com SD (SOUZA, 2017).

Fonte: Elaboração própria

\section{CONSIDERAÇÕES FINAIS}

Diante dos dados encontrados, percebeu-se que, na fala dos sujeitos participantes desta pesquisa, ocorrem tanto processos de substituição quanto de estrutura silábica, confirmando nossa hipótese.

Além disso, podemos constatar que os processos fonológicos ocorrem de forma assistemática, isto é, ora um segmento sofre processo fonológico, ora é realizado de forma esperada. Isto mostra que os PFs não são resultados da não aquisição de traços, como ocorre nos primeiros anos de vida da criança, quando o inventário fonológico ainda não está completo.

Tendo em vista que temos como pressuposto que os sujeitos participantes já adquiriram todo o sistema fonológico da língua, considerando que já passaram da idade de aquisição, depreendemos que os PFs são resultados da dificuldade por parte deles em produzir os sons da fala, que decorre das peculiaridades do trato vocal e a hipotonia generalizada que a pessoa com SD apresenta, bem como de uma dificuldade de planejamento motor.

Contudo, o fato de haver aspectos anatômicos ou fisiológicos e até mesmo cognitivos comprometendo o mecanismo de produção da fala da pessoa com SD não exclui a possibilidade de haver desvio fonológico nos sujeitos participantes. $\mathrm{O}$ que nos levar a pensar nessa possibilidade são as co-ocorências de processos fonológicos que indicam a falta de especificação de certos traços.

Se considerarmos os PFs encontrados na produção oral de cada sujeito ( $\mathrm{Cf}$. Quadro 2), perceberemos que a co-ocorrência de PFs relacionados ao mesmo traço - como é o caso dos PFs de: sonorização e dessonorização, lateralização e rotacismo - pode ser evidência de que ainda não houve, por parte de alguns dos sujeitos investigados, a especificação fonológica de alguns traços - conforme observam-se nos dados de LSF1, TSF3, ESF4, ASM5 (Cf. Quadro 2). 
A não especificação de traços indica que, no sistema fonológico dos sujeitos citados, a oposição definida no sistema da língua pelo traço $[ \pm$ sonoro $]$ e $[ \pm$ lateral $]$ não está estabelecida.

Além disso, observamos a tendência à simplificação de sílabas complexas, assim como, dificuldades na estruturação da sequência sintagmática dos elementos das sílabas, ou redução da quantidade de sílabas da palavra.

Além disso, ressaltamos que, apesar de verificarmos que todos os sujeitos apresentam PFs na produção, não se percebeu uma homogeneidade nas suas falas, pois houve tanto indivíduos que apresentaram até 14 processos na sua produção oral, quanto um sujeito que apresentou apenas um processo. Os sujeitos que apresentaram menos processos (NSF2 e FSM8) produziram apenas processos de estrutura silábica (Cf. Quadro 2).

Essa constatação é bastante pertinente, pois nos leva a atentarmos ao fato de que os indivíduos com SD podem apresentar diferentes graus de comprometimento da fala, e, sendo assim, eventos externos, como terapias de fala, podem influenciar a melhora da produção oral, desde que considerem cada aspecto e singularidades da produção e da dificuldade dos indivíduos.

\section{REFERÊNCIAS}

BOERSMA, P.; WEENINK, D. Praat: doing phonetics by computer - Version 4.4.23-Computer program, retrieved 12 June 2006. Disponível em: http://www.praat.org.

CLEMENTS, G. N. The geometry of phonological features. Phonology Year-book, London, n. 2, pp. 225-252, 1985.

CLEMENTS, G. N; HUME, Elizabet, V. The Internal Organization of Speech Sounds. The Handbook of Phonological Theory. Glodsmith, John A. Blackwell Publishing, 1995. Blackwell Reference Online.

CLELAND, Joanne. ET AL. Relationship between speech, oromotor, language and cognitive abilities in children with Down's syndrome. Int. J. Lang. Comm. Dis, v. 45, n. 1, 2010.

COLLISCHONN, Gisela. Proeminência acentual e estrutura silábica: seus efeitos em fenômenos do português brasileiro. In: ARAÚJO, Gabriel A. $O$ acento $m$ português: abordagens fonológicas. São Paulo: Parábola, 2007, pp. 195-223.

HAMILTON, C. Investigation of the articulatory patterns of young adults with Down syndrome using electropalatography. Down syndrome research and practice, Portsmouth, vol 1, n. 1, pp. 15-28, 1993.

KENT, Ray. D.; VORPERIAN, Houri. K. Speech impairment in Down syndrome: a review. J Speech lang lear Res. v. 56, n. 1, 2013 pp. 178-210.

KUMIN, Libby; et al. A longitudinal study of the emergence of phonemes in children with Down syndrome. Journal of Communication Disorders. 1994, pp. 293-303.

MATZENAUER, Carmen. L. B.; MIRANDA, Ana R. M. 2009. Traços distintivos e a aquisição das vogais do PB. Hora, Dermeval da. (ed.), Vogais no ponto mais oriental das Américas. Paraíba, Ideia, pp. 37-55. 
MUSTACCHI, Z.; ROZONE, G. Síndrome de Down: aspectos clínicos e odontológicos. São Paulo: Cid, 1990 .

MUSTACCHI, Zan. Síndrome de Down: MUSTACCHI, Zan.; PERES, S. Genética baseada em evidências: síndromes e heranças. São Paulo: Cid, pp. 818-894, 2000.

OLIVEIRA, Marian et al. Processos fonológicos na escrita da pessoa com síndrome de Down. XI Colóquio do Museu Pedagógico, Vitória da Conquista- Ba, 2015, pp. 2647-2663.

OLIVEIRA, Marian. Sobre a produção vocálica na síndrome de Down: descrição acústica e inferências articulatórias.2011. 309f. Tese (Doutorado em Linguística) - Instituto de Estudos da Linguagem, Universidade Estadual de Campinas. Campinas, 2011.

OLIVEIRA, Marian; PACHECO, Vera. Características acústicas da vogal /i/ produzida por sujeitos com síndrome de Down. Veredas - atemática. Juiz de Fora. V. 12. N ${ }^{\circ}$ 2, pp. 104-119, 2012.

OLIVEIRA, Marian; PACHECO, Vera. Características fonéticas e contrastes fonológicos em dados de fala de pessoas com down: perspectiva da geometria de traços. Revista Linguística (Online), v. 32, pp. 73-90, 2016.

PEREIRA, Luana P.; OLIVEIRA, Marian; PACHECO, Vera. Investigação Experimental da Vogal /a/ Produzida por sujeito com síndrome de Down. VII Seminário de Pesquisa em Estudos Linguísticos. V. Conquista- Bahia, 2012, pp. 503-510.

PEREIRA, Luana, P, et al. Avaliação acústico articulatória das vogais altas. In: XVII Congreso Internacional Asociación de Lingüística y Filología de América Latina, 2014, João Pessoa. Anais da Alfal. 2014. v. 1. pp. 744-754.

SELKIRK, Elisabeth. The syllable. In: HULST, H.; SMITH, Van Der. The structure of phonological representations (part. II). Dordrecht-Holland: Foris Publications, 1982, pp. 337-383.

SOUZA, Luana, P.P. Processos fonológicos na fala e na escrita de sujeitos com síndrome de Down: uma interpretação via Geometria de Traços e Teoria Métrica da Sílaba. 2017, 174f. Dissertação (Mestrado) - Universidade Estadual do Sudoeste da Bahia, Programa de Pós-Graduação em Linguística, Vitória da Conquista, 2017. 